\title{
Inflammatory cytokine profile of co-cultivated primary cells from the endometrium of women with and without endometriosis
}

\author{
ADRIANA LUCKOW INVITTI, EDUARDO SCHOR, RAFAEL MARTINS PARREIRA, ALEXANDER KOPELMAN, \\ GIL KAMERGORODSKY, GIOVANA APARECIDA GONÇALVES and MANOEL JOÃO BATISTA CASTELLO GIRÃO
}

Department of Gynecology, Paulista School of Medicine, Federal University of São Paulo, São Paulo, SP 04024-002, Brazil

Received November 7, 2017; Accepted March 6, 2018

DOI: $10.3892 / \mathrm{mmr} .2018 .9137$

\begin{abstract}
Endometriosis is a chronic gynecological disorder defined as the presence of endometrial tissue within extra-uterine sites. The primary symptoms are infertility and chronic pain. The inflammatory environment and aberrant immune responses in women with endometriosis may be directly associated with the initiation and progression of endometriotic lesions. In the present study, the secretion of inflammatory cytokines was evaluated in cultures of primary endometrial cells (ECs) isolated from the endometrium of women with and without endometriosis. The presence of endometriotic cells leads to alterations in the secretory profile of healthy ECs. The expression of the inflammatory cytokines interleukin (IL)-6 and IL-8 was significantly increased in endometriotic and co-cultured cells compared with healthy ECs. IL-6 expression was strongly correlated with IL-8 expression in endometriotic cells. IL-1 $\beta$ expression was increased on day 10 of co-culture to $48.30 \mathrm{pg} / \mathrm{ml}$ and may be associated with the long-term co-culture, rather than IL-6 and IL-8 expression. IL-6 expression was strongly correlated with cell number, whereas IL-8 expression was moderately correlated with cell number. Additionally, it was observed that co-cultured cells exhibited a different population of cells, with expression of the mesenchymal stem cell marker cell surface glycoprotein MUC18, indicating a putative role of endometrial mesenchymal stem cells in the secretion of cytokines and disease development. These results indicate a predominant role of primary endometriotic cells in the secretion of cytokines, which contributes to the disrupted peritoneal and endometrial environment observed in the women with endometriosis.
\end{abstract}

Correspondence to: Dr Adriana Luckow Invitti, Department of Gynecology, Paulista School of Medicine, Federal University of São Paulo, 608 Napoleão de Barros Road, Vila Clementino, São Paulo, SP 04024-002, Brazil

E-mail: adriana.invitti@gmail.com

Key words: endometriosis, endometrium, primary cells, co-culture, cytokines, endometrial environment

\section{Introduction}

Endometriosis is a chronic gynecological disorder defined as the presence of endometrial tissue within extra-uterine sites $(1,2)$. It affects $10-15 \%$ of women of reproductive age and results in a markedly reduced quality of life (3-5). The primary symptoms are infertility and chronic pain $(6,7)$. It is a hormone-dependent and chronic inflammatory disease $(1,2,8)$, indicating that the endometrium and the peritoneal environment are directly associated with its pathogenesis.

The progression of endometriosis is dependent on genetic, endocrine, immunological and environmental factors $(9,10)$. The endometrium, serum and peritoneal fluid of women with endometriosis have abnormal levels of inflammatory cytokines, angiogenic, growth and adhesion factors, and cancer-like molecules $(6,11,12)$. These soluble factors are thought to have predominant involvement in disease initiation and progression. Interleukin (IL)- $1 \beta$ has a proliferative effect on endometriotic cells that does not occur in healthy endometrial cells (13). IL-1 $\beta$ stimulates the production of IL-6 and IL- 8 in endometriotic cell cultures, which further induce proliferation $(14,15)$ and reduce the apoptotic rate (16-19). Additionally, IL-1 $\beta$ increases the shedding of intercellular adhesion molecule (ICAM)-1 from peritoneal mesothelial cells, indicating a role in the neovascularization mediated by IL-6 and vascular endothelial growth factor (VEGF) (20). Furthermore, higher levels of IL-1 $\beta$ may indicate the conversion of inflammation from an acute to a chronic form (21).

Tumor necrosis factor (TNF)- $\alpha$, IL-6, IL-8, IL-10, VEGF and C-C motif chemokine 2 (MCP-1) expression is increased in the peritoneal fluid of women with endometriosis $(11,18,21-24)$. TNF- $\alpha$ is associated with pluripotency mediation and inflammatory cytokine production, particularly IL-8, in endometriotic tissues (25). IL-8 increases the adhesion of endometrial stroma to extracellular matrix proteins, in addition to increasing metalloproteinase expression and proliferation (26-28). IL-8 may be a key cytokine in the progression of endometriotic lesions, by stimulating growth and indirectly protecting implants against apoptosis (18). IL-6 is secreted by endometrial cells and may have an important role in the pathology of endometriosis with interferon- $\gamma$. IL-6 increases macrophage expression of ICAM-1 in patients with endometriosis $(29,30)$. Increased peritoneal concentrations 
of IL-6 and IL-8 are associated with different stages of the disease $(23,31)$. In addition, the resistance to progesterone observed in endometriosis (32-34) is linked to the aberrant expression of cytokines $(35,36)$.

The aberrant peritoneal environment, in addition to discrepancies in apoptosis and proliferation, result in abnormal immune cell clearance in women with endometriosis, providing a longer survival of the endometrial cells regurgitated by uterine tubes and the establishment of endometrial implants $(5,24,31,37)$. Recently, the evaluation of peritoneal cytokines in patients with endometriosis indicated that the inflammatory environment observed in these patients is triggered by the establishment and growth of endometrial implants (38). Therefore, the present study investigated inflammatory cytokine secretion in the culture media of healthy and endometriotic primary cells. It was hypothesized that co-culture with endometriotic cells may lead to inflammatory cytokine secretion and phenotypic modifications in healthy endometrial cells associated with endometriosis implant establishment.

\section{Materials and methods}

Human tissues and cell culture. The protocol of the present study was approved by the Federal University of São Paulo ethical committee (registration no. 1044/11, São Paulo, Brazil). Written informed consent was obtained from all patients. Endometrial cells (ECs) from healthy individuals and patients with endometriosis were obtained from the Endometrium and Endometriosis Cell Bank of the Pelvic Pain and Endometriosis Unit of the Federal University of São Paulo. The selected samples were collected from August 2013 to April 2014. Human endometrium samples were collected from fertile cycling women aged 18-45 undergoing laparoscopic surgery for endometriosis stage IV (endometriosis group; $n=3$ ) and tubal ligation (control group; n=3). Patients had not taken exogenous hormones, given birth or breastfed for 3 months prior to surgery; patients with co-morbidities including teratoma, endometrial polyps or any other proliferative disease were excluded. The collected endometrial tissue was separated into two for either histological analysis $(39,40)$ (data not shown) or cell culture.

The tissue for cell culture was immediately placed in Dulbecco's modified Eagle's medium with nutrient mixture F12 (DMEM/F12; Thermo Fisher Scientific, Inc., Waltham, MA, USA) containing $400 \mathrm{U} / \mathrm{ml}$ penicillin and $400 \mu \mathrm{g} / \mathrm{ml}$ streptomycin (Gibco; Thermo Fisher Scientific, Inc.), stored at $4^{\circ} \mathrm{C}$ and processed within 2-24 h. The endometrial tissue was dissociated with 255 units of collagenase type IA (Sigma-Aldrich; Merck KGaA, Darmstadt, Germany) and 3 units of dispase (Gibco; Thermo Fisher Scientific, Inc.) in DMEM/F12 and was subsequently incubated for $40 \mathrm{~min}$ in a $37^{\circ} \mathrm{C}$ water bath under constant agitation. The cell suspension obtained was centrifuged at $500 \mathrm{x}$ g for $5 \mathrm{~min}$ at room temperature and the pellet was resuspended in $5 \mathrm{ml}$ EC medium containing DMEM/F12 at $\mathrm{pH} 7.4,1 \%$ Minimum Essential Medium non-essential amino acids (Gibco; Thermo Fisher Scientific, Inc.), $0.1 \mathrm{mmol} / 1$ 2-mercaptoethanol (Sigma-Aldrich; Merck KGaA), $100 \mu / \mathrm{ml}$ penicillin and $100 \mu / \mathrm{ml}$ streptomycin and 10\% fetal bovine serum (FBS; Gibco; Thermo Fisher Scientific, Inc.), and inoculated in a pre-coated $25 \mathrm{~cm}^{2}$ cell culture flask. The cells were grown

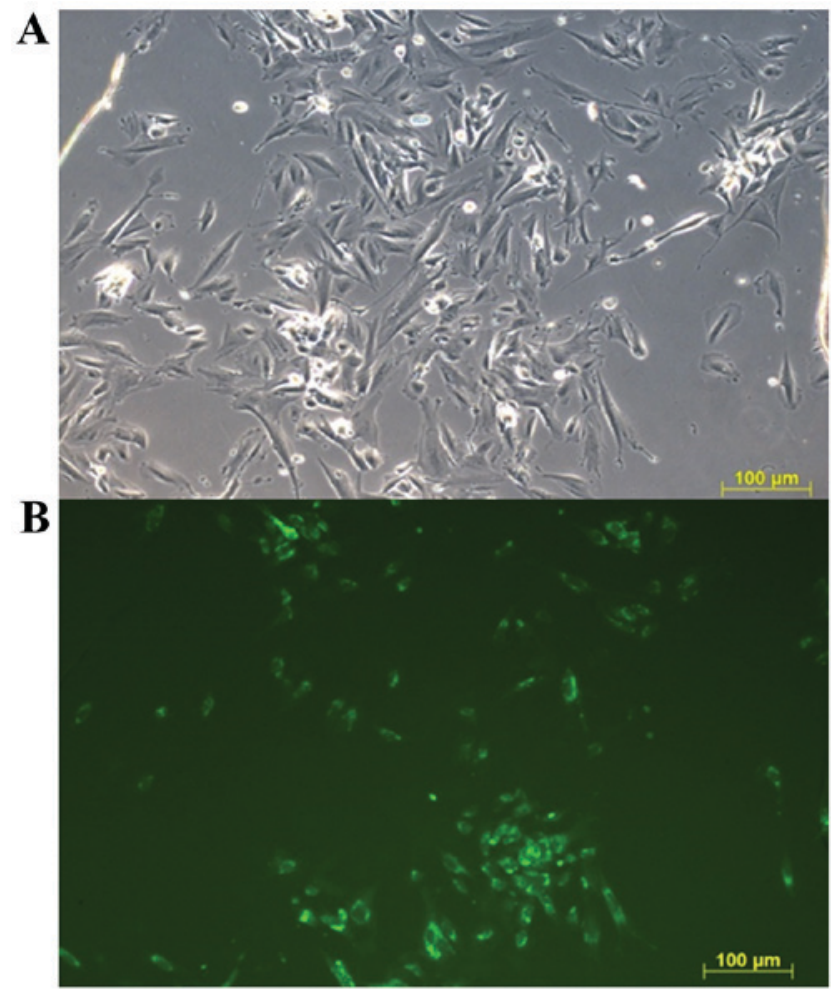

Figure 1. Representative fluorescent images of co-cultured ECs. Endometriotic ECs were unstained and healthy ECs were stained with Calcein AM $24 \mathrm{~h}$ after cell seeding. Calcein AM-stained cells are visualized in green. (A) Blank channel. (B) Green channel. Scale bar, $100 \mu \mathrm{m}$. ECs, endometrial cells.

in EC medium supplemented with $10 \% \mathrm{FBS}$ at $37^{\circ} \mathrm{C}$ until approximately $70 \%$ confluence was reached. At this stage, cells were subcultured. The cells were stored in liquid nitrogen.

Healthy and endometriotic cell co-culture. Co-cultures were performed in 12-well culture plates. Healthy ECs were pre-stained with $2 \mu \mathrm{g} / \mathrm{ml}$ Calcein-AM (Thermo Fisher Scientific, Inc., Waltham, MA, USA) for $30 \mathrm{~min}$ at $37^{\circ} \mathrm{C}$ with $5 \% \mathrm{CO}_{2}$. Cell number and viability were assessed with a Countess $^{\mathrm{TM}}$ Automated Cell Counter (Invitrogen; Thermo Fisher Scientific Inc.); $10 \mu 1$ cell suspension was thoroughly mixed with $10 \mu 10.4 \%$ Trypan Blue (Invitrogen; Thermo Fisher Scientific Inc.), then, $10 \mu \mathrm{l}$ was added to the chamber slide, the cells were settled for $30 \mathrm{sec}$ at room temperature prior to counting; according to the manufacturer's protocols. Healthy and endometriotic cells were mixed at a 1:1 ratio and seeded onto 12-well plates at a density of 5,000 cells $/ \mathrm{cm}^{2}$ and cultured in EC medium supplemented with $10 \%$ FBS for 10 days. The adhesion of green (healthy) and unstained (endometriotic) cells was reported by light microscopy (magnification, x 50, Axio Observer, Zeiss GmbH, Jena, Germany) $24 \mathrm{~h}$ after the initial cell seeding, the stained and non-stained cells were visually counted in four different fields for each triplicate. The culture medium was changed every 2 days and in the day prior to each control point (1st, 3rd, 7th and 10th days of culture). Cells were harvested during the 1st, 3rd, 7th and 10th days of culture, suspended in FBS with $10 \%$ dimethyl sulfoxide and stored in liquid nitrogen. The culture medium was collected and stored at $-80^{\circ} \mathrm{C}$ on days $1,3,7$ and 10 of culture. As a 

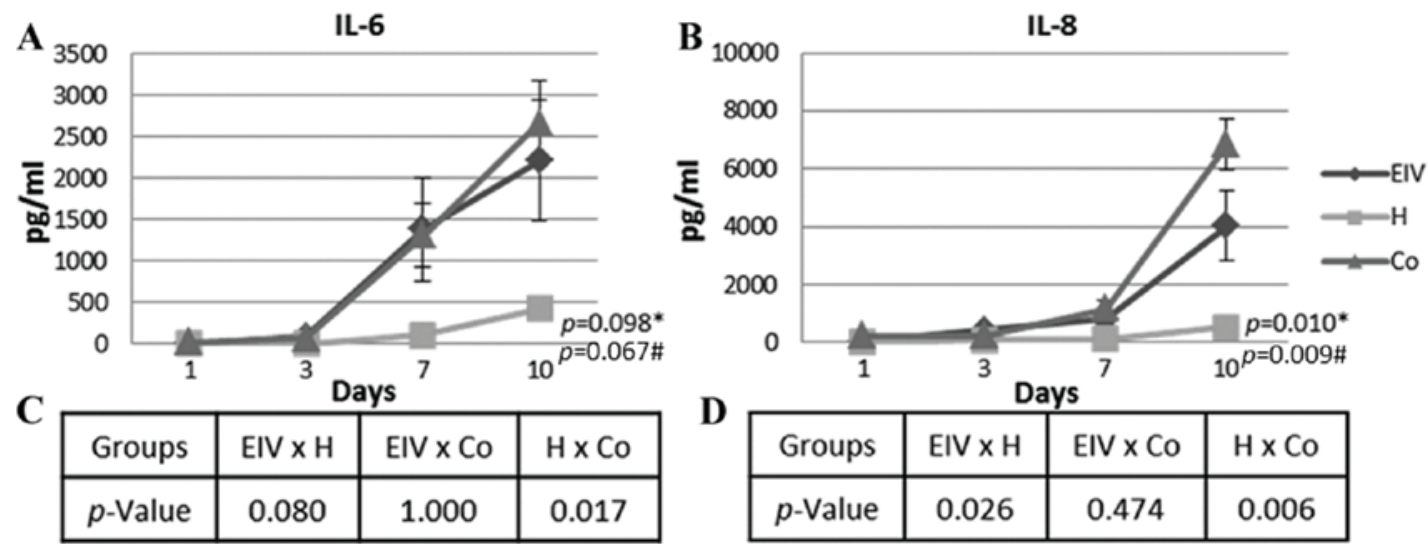

Figure 2. IL-6 and IL-8 culture medium secretion over time. (A) IL-6 concentration curves of each group. (B) IL-8 concentration curves of each group mean. (C) Statistical analysis of IL-6 and (D) IL-8 concentrations between groups. Data are presented as the mean \pm standard error of the endometriosis, healthy and co-cultured endometrial cells. "Repeated measures analysis of variance between the three groups. "Significance within subjects. IL, interleukin; EIV, endometriotic endometrial cells; $\mathrm{H}$, healthy cells, Co, co-cultured cells.

control, healthy and endometriotic cell groups were cultured separately as described above.

Culture medium cytokines detection. IL-1 $\beta$, IL-6, IL-8, IL-10, IL-12p70 and TNF- $\alpha$ expression levels were detected in the supernatant culture medium samples of single cell or co-cultured cells at days $1,3,7$ and 10 by flow cytometry using the phycoerythrin (PE)-conjugated beads from the Human Inflammatory Cytokine cytometric bead array kit (BD Biosciences, Franklin Lakes, NJ, USA). Events acquisition was performed in a CANTO II 6-colour flow cytometer (BD Biosciences) and data were analyzed with FlowJo software (version 10.0.7; FlowJo LLC, Ashland, OR, USA).

Flow cytometry of membrane markers. Healthy and endometriotic cells prior to the co-culture seeding and co-cultured cells harvested in the $1 \mathrm{st}, 3 \mathrm{rd}, 7 \mathrm{th}$ and 10 th days of culture were thawed on ice, centrifuged at $500 \mathrm{x} g$ for $5 \mathrm{~min} 4^{\circ} \mathrm{C}$, ressuspended in pH 7.4 1X PBS (Gibco; Thermo Fisher Scientific, Inc.) with 1\% FBS (Gibco; Thermo Fisher Scientific, Inc.) for blocking and incubated with directly conjugated antibodies for the surface markers aminopeptidase N [CD13-allophycocyanin (APC); cat no. 555394; BD Biosciences] at 1:5 dilution ratio and cell surface glycoprotein MUC18 [CD146-PE; cat no. 561013; BD Biosciences] at 1:20 dilution ratio for $1 \mathrm{~h}$ at $4^{\circ} \mathrm{C}$. Cells were washed with PBS $1 \mathrm{X} \mathrm{pH} 7.4$ and centrifuged at $500 \mathrm{x} \mathrm{g}$ for $5 \mathrm{~min} 4^{\circ} \mathrm{C}$, ressuspended in PBS $1 \mathrm{X} \mathrm{pH} \mathrm{7,4} \mathrm{and} \mathrm{subse-}$ quently analyzed with a BC FACSCanto II flow cytometer (BD Biosciences). The experiment controls were performed using imunoglubulin G1 isotype controls conjugated with PE (cat no. 550617) and APC (cat no. 550854) both at 1:5 working dilution ratio (BD Biosciences). Data were analyzed in FlowJo software (version 10.0.7; FlowJo LLC).

Statistical analysis. The data were analyzed with PASW Statistics 18.0.0 (IBM Corp., Armonk, NY, USA). All cell cultures were performed in experimental triplicates. Data are presented as the mean \pm standard error (SE). Cytokine data were analyzed with repeated measures analysis followed by Dunnett's T3 pairwise comparisons post-hoc test between the groups that presented unequal variances. Cell marker data were analyzed with repeated measures analysis followed by a Bonferroni corrected pairwise comparisons test within-subjects factors. The curves obtained were tested for sphericity using Mauchly's test and within-subject effects were corrected using the Greenhouse-Geisser test when sphericity assumption was violated. Simple and multiple linear regression were performed to identify the correlation between the variables obtained, where $0<\mathrm{r} \leq 0.25$ was null; $0.25<\mathrm{r} \leq 0.50$ was weakly correlated; $0.50<\mathrm{r} \leq 0.75$ was moderately correlated; and $0.75<\mathrm{r} \leq 1$ was strongly correlated (41). $\mathrm{P}<0.05$ was considered to indicate a statistically significant difference.

\section{Results}

Competitive relationship between healthy and endometriotic cells in co-culture systems. The adhesion of endometriotic (unstained) and healthy (Calcein-AM stained) cells in the first day of the co-culture is presented in Fig. 1. The amount of stained and not stained cells was visually semiquantitative evaluated in four microscopy fields in each triplicate. No observable difference was determined in the amount of endometriotic or healthy cells attached, indicating an equal number of each type of cell at the beginning of co-cultivation.

Inflammatory cytokine profile of healthy, endometriotic and co-cultured cells. The levels of inflammatory cytokines (IL-1 $\beta$, IL-6, IL-8, IL-10, IL-12p70 and TNF- $\alpha$ ) secreted into the culture medium were determined over time in endometriotic and healthy cells cultured alone, in addition to co-cultured cells. Insignificant levels of IL-10, IL12p70 and TNF- $\alpha$ were detected in the culture medium of all tested combinations of cells (data not shown). However, the IL-6 concentration increased over time in all groups (Fig. 2A). The variation observed for the endometriotic cells was similar to that observed in the co-cultured ECs $(\mathrm{P}=1.000$, across all time points). The healthy ECs had a significantly different profile of IL-6 secretion, compared with co-cultured ECs ( $P=0.017$, across all time points). As presented in Fig. 2, IL-6 secretion 
Table I. Multiple correlation coefficient between inflammatory cytokine expression and cell number in endometriotic and healthy endometrial cells individually and co-cultured over time.

\begin{tabular}{|c|c|c|c|c|c|c|}
\hline \multirow[b]{2}{*}{ Pairs } & \multicolumn{2}{|c|}{ Endometriosis } & \multicolumn{2}{|c|}{ Healthy } & \multicolumn{2}{|c|}{ Co-cultured cells } \\
\hline & $\mathrm{r}$ & P-value & $\mathrm{r}$ & P-value & $\mathrm{r}$ & P-value \\
\hline No. of cells and IL-6 & 0.87114 & 0 & 0.92528 & 0 & & \\
\hline No. of cells and IL- 8 & 0.60255 & 0.0001 & 0.53407 & 0.0087 & & \\
\hline IL-6 and IL- 8 (all time points) & 0.84211 & 0 & 0.50648 & 0.0137 & 0.6947 & 0 \\
\hline IL-1 $\beta$ and IL-6 (day 10) & & & & & 0.5565 & 0.1197 \\
\hline IL-1 $\beta$ and IL-8 (day 10) & & & & & 0.2158 & 0.5771 \\
\hline
\end{tabular}

IL, interleukin.
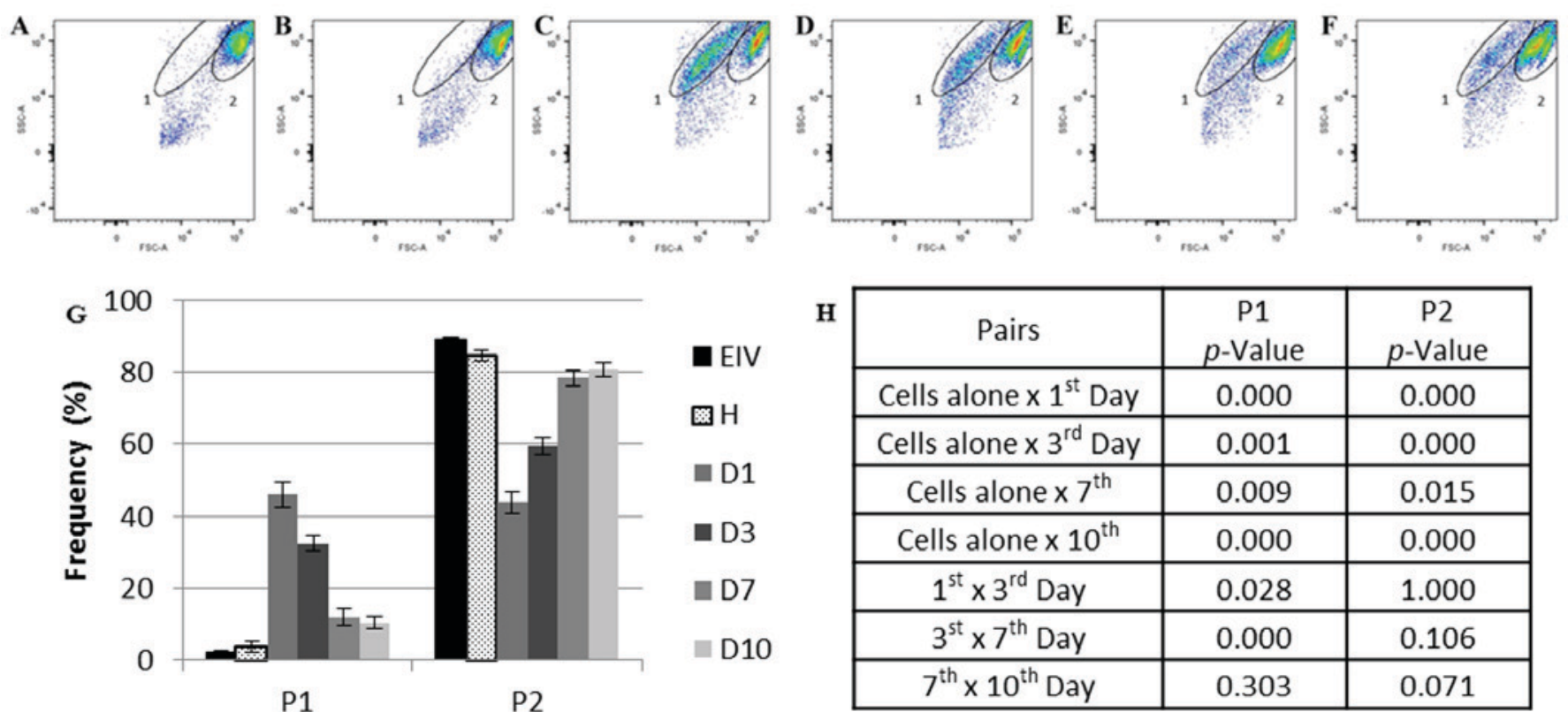

\begin{tabular}{|c|c|c|}
\hline Pairs & $\begin{array}{c}\text { P1 } \\
p \text {-Value }\end{array}$ & $\begin{array}{c}\text { P2 } \\
p \text {-Value }\end{array}$ \\
\hline Cells alone $\times 1^{\text {st }}$ Day & 0.000 & 0.000 \\
\hline Cells alone $\times 3^{\text {rd }}$ Day & 0.001 & 0.000 \\
\hline Cells alone $\times 7^{\text {th }}$ & 0.009 & 0.015 \\
\hline Cells alone $\times 10^{\text {th }}$ & 0.000 & 0.000 \\
\hline $1^{\text {st }} \times 3^{\text {rd }}$ Day & 0.028 & 1.000 \\
\hline $3^{\text {st }} \times 7^{\text {th }}$ Day & 0.000 & 0.106 \\
\hline $7^{\text {th }} \times 10^{\text {th }}$ Day & 0.303 & 0.071 \\
\hline
\end{tabular}

Figure 3. Flow cytometry analysis of the healthy, endometriotic and co-cultured ECs. (A) Endometriotic ECs cultivated alone prior to co-culture and (B) healthy ECs cultured alone prior to co-culture. (C) Co-cultured ECs at day 1, (D) day 3, (E) day 7 and (F) day 10. (G) Frequency of P1 and P2 during co-culture. (H) Statistical analysis of each population frequency between each day of co-culture and cells cultured alone. The elliptical delimitations 1 and 2 indicate the two populations delimited by differences in size and complexity in each sample. The images are representative for all samples. Data are presented as the mean of each sample group \pm standard error. ECs, endometrial cells; EIV, endometriotic ECs; D1, day 1 of co-culture; D3, day 3 of co-culture, D7, day 7 of co-culture; D10, day 10 of co-culture; FSC, forward scatter; H, healthy ECs; P1, population one; P2, population two; SSC, side scatter.

was higher in the endometriosis and co-culture groups. A strong correlation was detected between the number of cells and the concentration of IL- 6 in the medium of healthy and endometriotic cells (Table I).

Pro-angiogenic IL-8 was differentially secreted in healthy, endometriotic and co-cultured ECs (Fig. 2B). The most significant variation occurred from day 7 , when the concentration increased in all groups. The differences between the curves of IL-8 concentration were statistically significant $(\mathrm{P}=0.010)$. The secreted IL- 8 level in the healthy EC culture was significantly lower compared with the endometriosis $(\mathrm{P}=0.026$, across all time points) and co-cultured ( $\mathrm{P}=0.006$, across all time points) groups. Similar to the trend observed for IL-6, the secretion of IL- 8 was similar in the endometriotic and co-cultured cells ( $\mathrm{P}=0.474$, across all time points). The number of cells and IL- 8 concentration were moderately correlated in healthy and endometriotic cells (Table I). Additionally, there was a moderate correlation between IL- 6 and IL- 8 secretion in the healthy and co-cultured cells. A strong correlation between the secretion of these cytokines was observed in the endometriotic cells (Table I).

The co-cultured cells had $48.30 \mathrm{pg} / \mathrm{ml}$ (SE, 9.68) IL-1 $\beta$ at day 10 of culture (data not shown); IL-1 $\beta$ levels at days 1 , 3 and 7 were undetectable. The secretion of IL-1 $\beta$ appears to be associated with the effects of long-term co-culturing of the cells, although not directly to the secretion of IL-6 or IL-8 (Table I).

Population profile of co-cultured ECs. Flow cytometry analysis of the cells cultured alone and co-cultured cells using the size (forward scatter) and complexity (side scatter) parameters demonstrated the presence of two main populations in the 
samples: One and two. Population one represented $<5 \%$ of the total events collected in the healthy (Fig. 3A) and endometriosis (Fig. 3B) samples alone (2.95\%; SE, 0.44). The percentage of this population increased by 15 -fold in the first day of co-culture (Day 1, 45.93\%; SE, 3.58; $\mathrm{P}=0.000179$ vs. cells cultured alone; Fig. 3C). No population differences were observed in the ECs individually cultured over time (data not shown).

Population one diminished at day 3 (32.35\%; SE, 2.16; $\mathrm{P}=0.028412$ vs. day 1 of co-culture; Fig. 3D) and day 7 (11.89\%; SE, 2.33; $\mathrm{P}=0.000076$ vs. day 3 of co-culture; Fig. 3E) of co-culture and appeared to stabilize between days 7 and 10 (Fig. 3F) of culture (10.40\%; SE, 1.79; $\mathrm{P}=0.302732$, day 7 vs. day 10 of co-culture).

Population two was more prevalent in the EC samples cultured alone (87.36\%; SE, 1.52; Fig. 3A and B). This percentage reduced by one-half on day 1 of co-culture $(43.78 \%$; SE, 3.03; $\mathrm{P}=0.000264$ vs. cells cultured alone; Fig. 3C). Despite this population size increasing over time (day 3, 59.50\%; $\mathrm{SE}, 2.41 ; \mathrm{P}=0.000449$ vs. cells cultured alone; day 7, 78.36\%; $\mathrm{SE}, 2.19 ; \mathrm{P}=0.015462$ vs. cells cultured alone; Fig. 3D and $\mathrm{E}$, respectively), the original population size detected in ECs cultured alone was not completely reestablished at day 10 of co-culture $(80.73 \%$; SE, $2.06 ; \mathrm{P}=0.000622$ vs. cells cultured alone; Fig. 3F).

Phenotypic profile of co-cultured ECs over time. According to the variations detected within the populations of ECs cultured alone or co-cultured, the stromal endometrial cell marker CD13 $(42,43)$ and the endometrial mesenchymal stem cell (eMSC) marker CD146 (44-46) were selected to further characterize these populations. CD13 expression was not significantly different within co-cultured or individually cultured populations (Fig. 4).

The expression of eMSC marker CD146 varied significantly over time (Fig. 5). Population one had negligible expression of CD146, with the mean expression at all time points in the co-cultured group of $1.21 \%$ (SE, 0.25 ). In population two, an increase in CD146 expression was observed between days 1 and 7 of co-culture (1st vs. 3 rd days, $P=0.037$; 3rd vs. 7 th days, $\mathrm{P}=0.017)$, with a slight decrease in expression between days 7 and 10 of co-culture $(\mathrm{P}=0.071)$. The expression of CD146 in population 2 at 1st day of co-culture was more similar to endometriotic cells $(\mathrm{P}=0.102010)$ compared with healthy $\mathrm{ECs}$ $(\mathrm{P}=0.051579)$ (data not shown). These results demonstrated that population two was predominantly composed of eMSCs, and that there was an increase in these cells when healthy and endometriotic cells were co-cultured.

\section{Discussion}

The first and most acceptable theory for endometriosis pathogenesis was proposed almost a century ago (47), yet the pathophysiology of this disease remains unclear. As a hormone-dependent and chronic inflammatory disease $(1,2,8)$, cytokines and soluble factors appear to serve an important role in its pathophysiology. The inflammatory content of the peritoneal fluid and serum, in addition to the eutopic and ectopic endometrium has been extensively studied $(6,11,12,18,21,23,38)$. However, there are a number of questions which remain unanswered.
The increased levels of inflammatory cytokines in the peritonealfluid,serumandendometrium of women withendometriosis has been reported in numerous studies $(18,23,28,31,38,48)$. The principal identified factors include TNF- $\alpha$, IL-6, IL-8, IL-10, VEGF and MCP-1 (11,18,21-24,49-51). In the present study, increased levels of IL- 6 and IL- 8 were observed in endometriotic cells cultured alone and in co-culture with healthy ECs, compared with individually cultured healthy ECs. The levels of IL-1 $\beta$ were additionally increased in the co-culture at day 10.

Sikora et al (18) proposed that IL-8 is important for progression of endometriosis. IL- 8 increases the adhesion of endometrial stroma to extracellular matrix proteins, in addition to metalloproteinase expression and cell proliferation (26-28). The surgical excision of endometrial lesions leads to a decrease in the peritoneal levels of IL-8 (38). In the present study, increased secretion of IL-8 by endometriotic and co-cultured cells was detected. A previous study indicated that peritoneal immune cells, particularly macrophages, are the main source of IL-8 (18). The results of the present study indicated that ECs additionally contribute to IL-8 secretion. Furthermore, IL-8 expression was moderately correlated with cell number and IL-6 expression, suggesting that IL- 8 secretion may be independent of cell proliferation and IL-6 levels.

IL- 6 is secreted by the endometrium and implants, and is involved in diverse aspects of reproductive physiology, including ovarian steroid production, foliculogenesis and early embryonic implantation $(28,49,52,53)$. IL- 6 is associated with the increased expression of ICAM-1 by macrophages in patients with endometriosis $(29,30)$. The present study demonstrated that the secretion of IL- 6 by endometriotic cells was higher compared with healthy or co-cultured ECs. The increased levels of IL- 6 were strongly correlated with cell numbers, indicating that the increased proliferative rate may be due to IL-6 signaling. The increased cell number also increases the IL- 6 secretion. It has been well established that endometriotic stromal cells have a higher proliferative rate compared with healthy endometrial stromal cells $(54,55)$. This increase in proliferation rate may be mediated by IL-6.

The levels of IL- 6 may be associated with IL- $1 \beta$ secretion (20). The results of the present study revealed the presence of IL-1 $\beta$ at day 10 of co-culture only, with no significant alterations in the expression of IL-1 $\beta$ in individually cultured healthy or endometriotic cells. Furthermore, there was no statistically significant correlation between IL- 6 and IL-1 $\beta$ expression. The secretion of IL- $1 \beta$ by the primary co-cultured ECs may be associated with long-term co-culture, which may indicate a switch from an acute to chronic inflammatory response in the endometrial cells (21). The proliferative effects of IL- $1 \beta$ have been reported in endometriotic cells (13). Furthermore, an increase in IL-1B expression occurs in the co-culture of endometrial primary cells and MSCs (56).

The endometrium contains MSCs that are involved in the cyclical regeneration of this tissue (57-59). The role of stem cells in the pathogenesis of endometriosis has been reported $(37,60,61)$. The most widely accepted theory for endometriosis pathogenesis was proposed by Sampson (47) and indicates that the implants establish from cells undergoing 

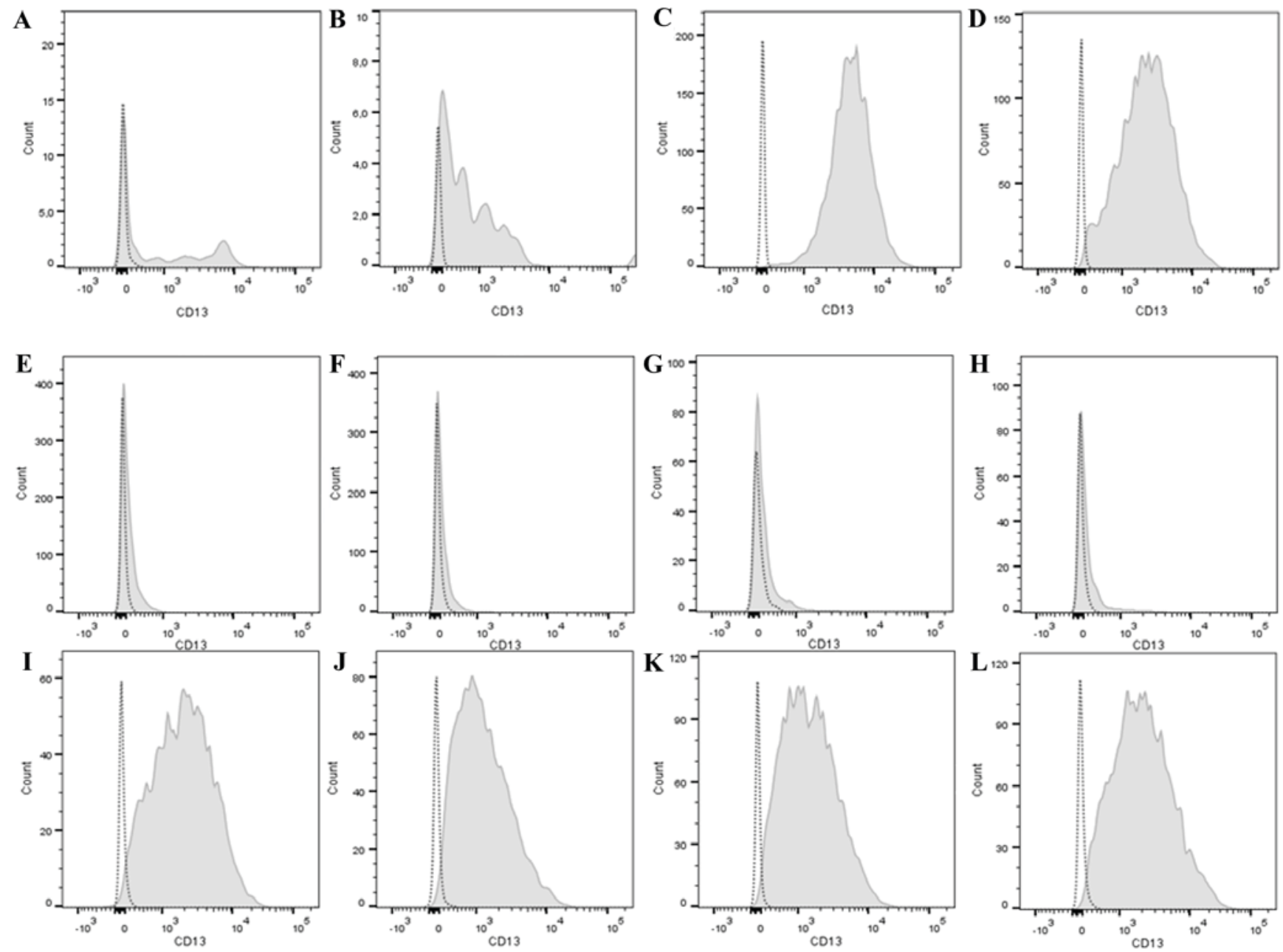

$\mathbf{M}$

CD13

$\mathbf{N}$

Population

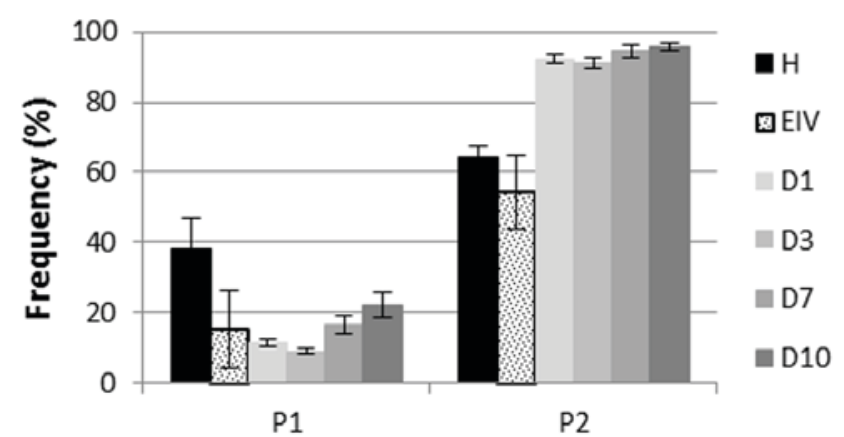

\begin{tabular}{|c|c|c|}
\hline Co-culture & $\begin{array}{c}\text { P1 } \\
p \text {-Value }\end{array}$ & $\begin{array}{c}\text { P2 } \\
p \text {-Value }\end{array}$ \\
\hline $1^{\text {st }} \times 3^{\text {rd }}$ Day & 0.295 & 1.000 \\
\hline $3^{\text {st }} \times 7^{\text {th }}$ Day & 0.092 & 0.058 \\
\hline $7^{\text {th }} \times 10^{\text {th }}$ Day & 0.297 & 1.000 \\
\hline
\end{tabular}

Figure 4. CD13 expression in each cell population. In the histograms, light gray dotted lines indicate background fluorescence obtained with the isotype control immunoglobulin G1. CD13 expression is represented by the light gray filled areas. The $\mathrm{x}$ axis represents fluorescence intensity and the y axis represents cell count. (A) Histogram for CD13 expression in P1 of healthy ECs and (B) EIV. (C) Histogram for CD13 expression in P2 of healthy ECs and (D) EIV. (E) Histogram for CD13 expression on P1 at day 1, (F) day 3, (G) day 7 and (H) day 10 of EC co-culture. (I) Histogram for CD13 expression on P2 at day 1, (J) day 3, (K) day 7 and (L) day 10 of EC co-culture. (M) CD13 expression in each population. (N) Statistical analysis of CD13 expression between each day of co-culture for P1 and P2. Data are presented as the mean of each sample group \pm standard error. ECs, endometrial cells; CD13, aminopeptidase N; P1, population one; P2, population two; H, healthy ECs; EIV, endometriotic ECs; D1, day 1 of co-culture; D3, day 3 of co-culture; D7, day 7 of co-culture; D10, day 10 of co-culture.

retrograde menstruation; this theory alone is unable to explain all clinical presentations of the disease. The combined theories of Sampson (47) and the involvement of stem cells provide a better explanation for endometriosis physiopathology. The dysregulation of eMSCs has been proposed as a key mechanism of endometriosis, in concordance with the retrograde menstruation theory (62).
The mesenchymal stem cell marker CD146 (46) was used in the present study in order to identify the presence of MSCs in the pool of primary cells, and to report the variations in the MSC population during co-culture. An increase in the number of eMSCs detected by CD146 expression was observed in the co-culture system. These alterations in CD146 expression over time, together with the alterations in cytokine secretion, may 

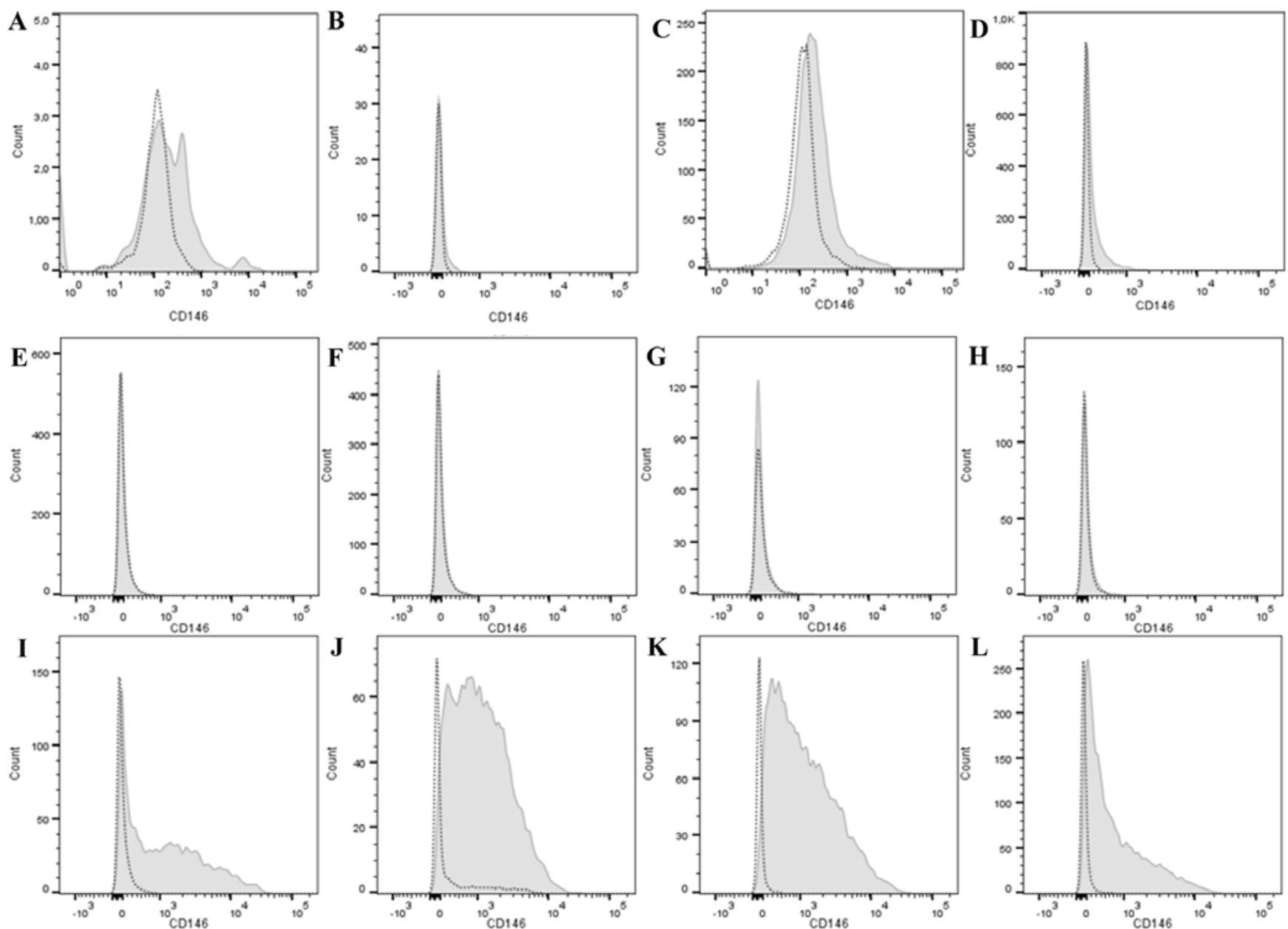

M

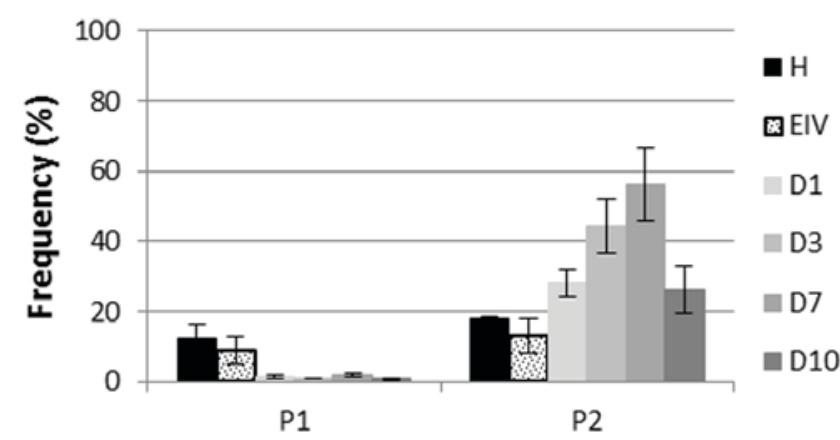

Population

\begin{tabular}{|c|c|c|}
\hline Co-culture & $\begin{array}{c}\text { P1 } \\
p \text {-Value }\end{array}$ & $\begin{array}{c}\text { P2 } \\
p \text {-Value }\end{array}$ \\
\hline $1^{\text {st }} \times 3^{\text {rd }}$ Day & 1.000 & 0.037 \\
\hline $3^{\text {st }} \times 7^{\text {th }}$ Day & 0.038 & 0.017 \\
\hline $7^{\text {th }} \times 10^{\text {th }}$ Day & 0.394 & 0.071 \\
\hline
\end{tabular}

Figure 5. CD146 expression in cell each population. In the histograms, light gray dotted lines indicate background fluorescence obtained with the isotype control immunoglobulin G1. CD146 expression is represented by the light gray filled areas. The $\mathrm{x}$ axis represents fluorescence intensity and the $\mathrm{y}$ axis represents cell count. (A) Histogram for CD146 expression in P1 of healthy ECs and (B) EIV. (C) Histogram for CD146 expression in P2 of healthy ECs and (D) EIV. (E) Histogram for CD146 expression on P1 at day 1, (F) day 3, (G) day 7 and (H) day 10 of EC co-culture. (I) Histogram for CD146 expression on P2 at day $1,(\mathrm{~J})$ day 3, (K) day 7 and (L) day 10 of EC co-culture. (M) CD146 expression in each population. (N) Statistical analysis of CD146 expression between each day of co-culture for P1 and P2. Data are presented as the mean of each sample group \pm standard error. ECs, endometrial cells; CD146, cell surface glycoprotein MUC18; P1, population one; P2, population two; H, healthy; ECs, EIV, endometriosis ECs; D1, day 1 of co-culture; D3, day 3 of co-culture; D7, day 7 of co-culture; D10, day 10 of co-culture.

indicate the involvement of MSCs in cytokine secretion. A pool of primary cells at a low passage number were selected, as this contained various cell populations and was more similar to the composition of the eutopic endometrium. In previous work (56), the co-culture of umbilical cord blood MSCs with primary endometrial cells resulted in increased IL-1 $\beta$ expression. Furthermore, co-culture eliminated the effect of p27 gene therapy on endometriotic stromal cells. These observations, together with the identification and characterization of endometrial MSCs $(37,45,58,60,63)$, have provided an insight into the involvement of MSCs in endometriosis pathogenesis. In the present study, the co-cultivation of a pool of healthy and 
diseased primary cells, containing endometrial MSCs, led to the secretion of cytokines that may be directly involved in the pathogenesis of endometriosis. This supports the theory that eMSCs have an important role in the secretion of cytokines and endometriosis.

MSCs express CD13 $(44,46)$, which is additionally expressed by stromal endometrial cells $(42,43)$. CD13 is an $\mathrm{N}$-aminopeptidase involved in the inactivation of IL-8 (64). Conflictingly, increased levels of CD13 expression due to cell-to-cell contact may be associated with IL-8 inactivation resistance (65) and the inhibition of apoptosis mediated by IL-8 (66). In the present study, CD13 expression was not significantly different between the co-cultured and individually cultured cells, indicating no physiological implications. Therefore, CD13 expression in the present study may be indicative of fibroblastoid cells.

Furthermore, the present study observed that a mixed cell population derived from the endometrium exhibited a secretory profile similar to that of endometriotic cells, even in the presence of healthy ECs. The results obtained demonstrated that the communication between endometriotic and healthy cells results in a secretory profile similar to what is reported in the peritoneal fluid of women with endometriosis $(24,28,31,52)$. The increased secretion of IL- 6 and IL- 8 is additionally associated with the progesterone resistance observed in endometriosis $(32,34)$. The results of the present study support this finding, as the endometriotic cells secreted higher levels of IL-6 and IL- 8 compared with the healthy cells. Additionally, the findings of the present study were consistent with the retrograde menstruation theory and clarified certain aspects of the disrupted peritoneal environment of women with endometriosis. For example, despite the presence of healthy endometrial cells in retrograde menstruation, the presence of endometriotic cells may be decisive in the secretory profile of the cell pool $(18,21,37)$. The endometrial cells regurgitated into peritoneal cavity may be responsible for the induction of the aberrant cytokine profile observed in the peritoneal fluid and eutopic endometrium of women with endometriosis $(18,19,21,23,37,38)$. The variations observed in the $\mathrm{CD}_{146^{+}}$population support the putative role of eMSCs in the pathogenesis of endometriosis.

The secretion alterations observed in the individually cultured ECs and the co-culture indicate a critical role for ectopic endometrial cells in the initiation of peritoneal environment disruption, which is in accordance with a recently published report (38). Thus, the cytokine profile observed may not only be generated by molecules secreted from immune cells. The main limitation of the present study is that, as an in vitro study, the effects of EC-secreted cytokines on immune cells present in the peritoneum of women with endometriosis was not demonstrated. Studies which isolate each population of cells observed in the present study may clarify the cell type responsible for the secretion of the cytokines or reveal the association between healthy and disease cell contact.

In accordance to previous research $(18,19,21,23,37,38)$, the findings of the present study suggest that the soluble factors secreted by endometriotic cells may have an important role in the disruption of the cell cycle and in the establishment of the peritoneal environment of women with endometriosis. The endometriotic cell pool may be responsible for the establishment of an inflammatory peritoneal environment favorable to the initiation and progression of endometrial cell adhesion and clustering.

\section{Acknowledgements}

We thank Colsan Blood Bank (São Paulo, Brazil) for all the technical support.

\section{Funding}

The present study was supported by the São Paulo Research Foundation (grant no. 2011/14683-7) and the Brazilian National Council of Technological and Scientific Development (grant no. 480303/2013-4).

\section{Availability of data and materials}

The datasets used and/or analyzed during the current study are available from the corresponding author on reasonable request.

\section{Authors' contributions}

ALI, GAG, MJBCG and ES provided major contributions to the conception and design of the present study. ALI, RMP, AK and GK conducted the collection of samples, experimentation and acquisition of data. ALI and ES were involved in analysis and interpretation of data. All authors were involved in manuscript drafting and critical discussion, as well as in the final approval of the version to be published.

\section{Ethics approval and consent to participate}

The protocol of the present study was approved by the Federal University of São Paulo ethical committee (São Paulo, Brazil). Written informed consent was obtained from all patients.

\section{Consent for publication}

Not applicable.

\section{Competing interests}

The authors declare that they have no competing interests.

\section{References}

1. Ulukus M, Cakmak H and Arici A: The Role of Endometrium in Endometriosis. J Soc Gynecol Investig 13: 467-476, 2006.

2. Falconer H, D'Hooghe T and Fried G: Endometriosis and genetic polymorphisms. Obstet Gynecol Surv 62: 616-628, 2007.

3. Eskenazi B and Warner ML: Epidemiology of endometriosis. Obstet Gynecol Clin North Am 24: 235-258, 1997.

4. Vinatier D, Cosson M and Dufour P: Is endometriosis an endometrial disease? Eur J Obstet Gynecol Reprod Biol 91: 113-125, 2000.

5. Bulun SE: Endometriosis. N Engl J Med 360: 268-279, 2009

6 . Burney RO and Giudice LC: Pathogenesis and pathophysiology of endometriosis. Fertil Steril 98: 511-519, 2012.

7. Giudice LC and Kao LC: Endometriosis. Lancet 364: 1789-1799, 2004.

8. Berkley KJ, Rapkin AJ and Papka RE: The Pains of Endometriosis. Science 308: 1587-1589, 2005. 
9. Trovó de Marqui AB: Genetic polymorphisms and endometriosis: Contribution of genes that regulate vascular function and tissue remodeling. Rev Assoc Med Bras 58: 620-32, 2012 (In English, Portuguese).

10. Kobayashi H, Yamada Y, Morioka S, Niiro E, Shigemitsu A and Ito F: Mechanism of pain generation for endometriosis-associated pelvic pain. Arch Gynecol Obstet 289: 13-21, 2014.

11. Ilie I and Ilie R: Cytokines and endometriosis-the role of immunological alterations. Biotechnol Mol Biol Nanomedicine 1: 8-19, 2013 .

12. Gazvani R and Templeton A: Peritoneal environment, cytokines and angiogenesis in the pathophysiology of endometriosis. Reproduction 123: 217-26, 2002.

13. Lebovic DI, Baldocchi RA, Mueller MD and Taylor RN: Altered expression of a cell-cycle suppressor gene, Tob-1, in endometriotic cells by cDNA array analyses. Fertil Steril 78: 849-854, 2002.

14. Bersinger NA, Günthert AR, McKinnon B, Johann S and Mueller MD: Dose-response effect of interleukin (IL)-1 $\beta$, tumour necrosis factor (TNF)- $\alpha$, and interferon- $\gamma$ on the in vitro production of epithelial neutrophil activating peptide-78 (ENA-78), IL-8, and IL-6 by human endometrial stromal cells Arch Gynecol Obstet 283: 1291-1296, 2011.

15. Yoshino O, Izumi G, Shi J, Osuga Y, Hirota Y, Hirata T, Harada M, Nishii O, Koga K and Taketani Y: Activin-A is induced by interleukin- $1 \beta$ and tumor necrosis factor- $\alpha$ and enhances the mRNA expression of interleukin- 6 and protease-activated receptor-2 and proliferation of stromal cells from endometrioma. Fertil Steril 96: 118-121, 2011.

16. Bilotas M, Meresman G, Buquet R, Sueldo C and Barañao RI: Effect of vascular endothelial growth factor and interleukin-1beta on apoptosis in endometrial cell cultures from patients with endometriosis and controls. J Reprod Immunol 84: 193-198, 2010.

17. Vetvicka V, Laganà AS, Salmeri FM, Triolo O, Palmara VI, Vitale SG, Sofo V and Králíčková M: Regulation of apoptotic pathways during endometriosis: From the molecular basis to the future perspectives. Arch Gynecol Obstet 294: 897-904, 2016.

18. Sikora J, Smycz-Kubańska M, Mielczarek-Palacz A and Kondera-Anasz Z: Abnormal peritoneal regulation of chemokine activation-The role of IL-8 in pathogenesis of endometriosis. Am J Reprod Immunol 77, 2017.

19. Gonçalves GA, Camargo-Kosugi CM, Bonetti TC, Invitti AL, Girão MJ, Silva ID and Schor E: p27kip1 overexpression regulates VEGF expression, cell proliferation and apoptosis in cell culture from eutopic endometrium of women with endometriosis. Apoptosis 20: 327-335, 2015.

20. Kyama CM, Overbergh L, Mihalyi A, Meuleman C, Mwenda JM, Mathieu C and D'Hooghe TM: Endometrial and peritoneal expression of aromatase, cytokines, and adhesion factors in women with endometriosis. Fertil Steril 89: 301-310, 2008

21. Sikora J, Mielczarek-Palacz A and Kondera-Anasz Z: Association of the precursor of interleukin- $1 \beta$ and peritoneal inflammation-role in pathogenesis of endometriosis. J Clin Lab Anal 30: 831-837, 2016

22. May CD, Sphyris N, Evans KW, Werden SJ, Guo W and Mani SA: Epithelial-mesenchymal transition and cancer stem cells: A dangerously dynamic duo in breast cancer progression. Breast Cancer Res 13: 202, 2011.

23. Fan YY, Chen HY, Chen W, Liu YN, Fu Y and Wang LN Expression of inflammatory cytokines in serum and peritoneal fluid from patients with different stages of endometriosis. Gynecol Endocrinol: 1-6, 2018 (Epub ahead of Print).

24. Jørgensen H, Hill AS, Beste MT, Kumar MP, Chiswick E, Fedorcsak P, Isaacson KB, Lauffenburger DA, Griffith LG and Qvigstad E: Peritoneal fluid cytokines related to endometriosis in patients evaluated for infertility. Fertil Steril 107: 1191-1199.e2, 2017.

25. Sakamoto Y, Harada T, Horie S, Iba Y, Taniguchi F, Yoshida S, Iwabe $\mathrm{T}$ and Terakawa $\mathrm{N}$ : Tumor necrosis factor-alpha-induced interleukin-8 (IL-8) expression in endometriotic stromal cells, probably through nuclear factor-kappa B activation: Gonadotropin-releasing hormone agonist treatment reduced IL- 8 expression. J Clin Endocrinol Metab 88: 730-735, 2003.

26. Garcia-Velasco JA and Arici A: Interleukin-8 stimulates the adhesion of endometrial stromal cells to fibronectin. Fertil Steril 72: 336-340, 1999.

27. Arici A, Seli E, Zeyneloglu HB, Senturk LM, Oral E and Olive DL: Interleukin-8 induces proliferation of endometrial stromal cells: A potential autocrine growth factor. J Clin Endocrinol Metab 83: 1201-1205, 1998
28. Kalu E, Sumar N, Giannopoulos T, Patel P, Croucher C, Sherriff E and Bansal A: Cytokine profiles in serum and peritoneal fluid from infertile women with and without endometriosis. J Obstet Gynaecol Res 33: 490-495, 2007.

29. Herington JL, Bruner-Tran KL, Lucas JA and Osteen KG Immune interactions in endometriosis. Expert Rev Clin Immunol 7: 611-626, 2011.

30. Young VJ, Brown JK, Saunders PT and Horne AW: The role of the peritoneum in the pathogenesis of endometriosis. Hum Reprod Update 19: 558-569, 2013.

31. Barcz E, Milewski Ł, Dziunycz P, Kamiński P, Płoski R and Malejczyk J: Peritoneal cytokines and adhesion formation in endometriosis: An inverse association with vascular endothelial growth factor concentration. Fertil Steril 97: 1380-1386.e1, 2012.

32. Young SL and Lessey BA: Progesterone function in human endometrium: Clinical perspectives. Semin Reprod Med 28: $5-16,2010$.

33. Barragan F, Irwin JC, Balayan S, Erikson DW, Chen JC, Houshdaran S, Piltonen TT, Spitzer TL, George A, Rabban JT, et al: Human endometrial fibroblasts derived from mesenchymal progenitors inherit progesterone resistance and acquire an inflammatory phenotype in the endometrial niche in endometriosis. Biol Reprod 94: 118, 2016

34. Lessey BA and Young SL: Homeostasis imbalance in the endometrium of women with implantation defects: The role of estrogen and progesterone. Semin Reprod Med 32: 365-375, 2014.

35. Wing LY, Chuang PC, Wu MH, Chen HM and Tsai SJ: Expression and mitogenic effect of fibroblast growth factor-9 in human endometriotic implant is regulated by aberrant production of estrogen. J Clin Endocrinol Metab 88: 5547-5554, 2003.

36. $\mathrm{Wu} \mathrm{MH}, \mathrm{Lu} \mathrm{CW}$, Chuang PC and Tsai SJ: Prostaglandin E2: The master of endometriosis? Exp Biol Med (Maywood) 235: 668-677, 2010.

37. Gargett CE, Schwab KE, Brosens JJ, Puttemans P, Benagiano G and Brosens I: Potential role of endometrial stem/progenitor cells in the pathogenesis of early-onset endometriosis. Mol Hum Reprod 20: 591-598, 2014

38. Monsanto SP, Edwards AK, Zhou J, Nagarkatti P, Nagarkatti M, Young SL, Lessey BA and Tayade C: Surgical removal of endometriotic lesions alters local and systemic proinflammatory cytokines in endometriosis patients. Fertil Steril 105: 968-977.e5, 2016.

39. Moen MH and Halvorsen TB: Histologic confirmation of endometriosis in different peritoneal lesions. Acta Obstet Gynecol Scand 71: 337-342, 1992.

40. Revised American Society for Reproductive Medicine classification of endometriosis: 1996. Fertil Steril 67: 817-821, 1997.

41. Vieira S: Introdução à Bioestatística. 4th edition. Elsevier Ltd, São Paulo, 2008

42. Kato Yoshimoto M, Kato K, Adachi S, Yamayoshi A, Arima T, Asanoma K, Kyo S, Nakahata T and Wake NK: Characterisation of side population cells in human normal endometrium. Hum Reprod 22: 1212-1223, 2007.

43. Seli E, Senturk LM, Bahtiyar OM, Kayisli UA and Arici A: Expression of aminopeptidase $\mathrm{N}$ in human endometrium and regulation of its activity by estrogen. Fertil Steril 75: 1172-1176, 2001.

44. Schwab KE and Gargett CE: Co-expression of two perivascular cell markers isolates mesenchymal stem-like cells from human endometrium. Hum Reprod 22: 2903-2911, 2007.

45. Schwab KE, Hutchinson P and Gargett CE: Identification of surface markers for prospective isolation of human endometrial stromal colony-forming cells. Hum Reprod 23: 934-943, 2008.

46. Gargett CE, Schwab KE, Zillwood RM, Nguyen HP and Wu D: Isolation and culture of epithelial progenitors and mesenchymal stem cells from human endometrium. Biol Reprod 80: 1136-1145, 2009.

47. Sampson JA: Peritoneal endometriosis due to the menstrual dissemination of endometrial tissue into the peritoneal cavity. Am J Obstet Gynecol 14: 422-469, 1927.

48. Milewski Ł, Dziunycz P, Barcz E, Radomski D, Roszkowski PI, Korczak-Kowalska G, Kamiński P and Malejczyk J: Increased levels of human neutrophil peptides 1,2, and 3 in peritoneal fluid of patients with endometriosis: Association with neutrophils, T cells and IL-8. J Reprod Immunol 91: 64-70, 2011.

49. Jacobs AL, Sehgal PB, Julian J and Carson DD: Secretion and hormonal regulation of interleukin- 6 production by mouse uterine stromal and polarized epithelial cells cultured in vitro. Endocrinology 131: 1037-1346, 1992. 
50. Szyllo K, Tchorzewski H, Banasik M, Glowacka E, Lewkowicz P and Kamer-Bartosinska A: The involvement of T lymphocytes in the pathogenesis of endometriotic tissues overgrowth in women with endometriosis. Mediators Inflamm 12: 131-138, 2003.

51. Kang YJ, Jeung IC, Park A, Park YJ, Jung H, Kim TD, Lee HG, Choi I and Yoon SR: An increased level of IL-6 suppresses NK cell activity in peritoneal fluid of patients with endometriosis via regulation of SHP-2 expression. Hum Reprod 29: 2176-2189, 2014

52. Harada T, Yoshioka H, Yoshida S, Iwabe T, Onohara Y, Tanikawa $M$ and Terakawa N: Increased interleukin-6 levels in peritoneal fluid of infertile patients with active endometriosis. Am J Obstet Gynecol 176: 593-597, 1997.

53. Bedaiwy MA, Falcone T, Sharma RK, Goldberg JM, Attaran M, Nelson DR and Agarwal A: Prediction of endometriosis with serum and peritoneal fluid markers: A prospective controlled trial. Hum Reprod 17: 426-431, 2002.

54. D'Amora P, Maciel TT, Tambellini R, Mori MA, Pesquero JB, Sato H, Girão MJ, Guerreiro da Silva ID and Schor E: Disrupted cell cycle control in cultured endometrial cells from patients with endometriosis harboring the progesterone receptor polymorphism PROGINS. Am J Pathol 175: 215-224, 2009.

55. Li MQ, Luo XZ, Meng YH, Mei J, Zhu XY, Jin LP and Li DJ: CXCL8 enhances proliferation and growth and reduces apoptosis in endometrial stromal cells in an autocrine manner via a CXCR1-triggered PTEN/AKT signal pathway. Hum Reprod 27: 2107-2116, 2012.

56. Gonçalves GA, Invitti AL, Parreira RM, Kopelman A, Schor E and Girão MJ: p27kip1 overexpression regulates IL-1 $\beta$ in the microenvironment of stem cells and eutopic endometriosis co-cultures. Cytokine 89: 229-234, 2017.

57. Prianishnikov VA: On the concept of stem cell and a model of functional-morphological structure of the endometrium Contraception 18: 213-223, 1978.
58. Gargett CE, Chan RW and Schwab KE: Endometrial stem cells. Curr Opin Obstet Gynecol 19: 377-383, 2007.

59. Sasson IE and Taylor HS: Stem cells and the pathogenesis of endometriosis. Ann N Y Acad Sci 1127: 106-115, 2008.

60. Gargett BE and Chan RW: Endometrial stem/progenitor cells and proliferative disorders of the endometrium. Minerva Ginecol 58 511-526, 2006.

61. Gargett CE and Gurung S: Endometrial mesenchymal stem/stromal cells, their fibroblast progeny in endometriosis, and more1. Biol Reprod 94: 129, 2016.

62. Hufnagel D, Li F, Cosar E, Krikun G and Taylor H: The role of stem cells in the etiology and pathophysiology of endometriosis. Semin Reprod Med 33: 333-340, 2015.

63. Gargett CE and Masuda H: Adult stem cells in the endometrium. Mol Hum Reprod 16: 818-834, 2010.

64. Kanayama N, Kajiwara Y, Goto J, el Maradny E, Maehara K, Andou $\mathrm{K}$ and Terao T: Inactivation of interleukin-8 by aminopeptidase N (CD13). J Leukoc Biol 57: 129-134, 1995.

65. Kehlen A, Egbert I, Thiele K, Fischer K, Riemann D and Langner J: Increased expression of interleukin-8 and aminopeptidase $\mathrm{N}$ by cell-cell contact: Interleukin- 8 is resistant to degradation by aminopeptidase N/CD13. Eur Cytokine Netw 12: 316-324, 2001 .

66. Mishima Y, Matsumoto-Mishima Y, Terui Y, Katsuyama M, Yamada M, Mori M, Ishizaka Y, Ikeda K, Watanabe J, Mizunuma N, et al: Leukemic cell-surface CD13/aminopeptidase $\mathrm{N}$ and resistance to apoptosis mediated by endothelial cells. J Natl Cancer Inst 94: 1020-1028, 2002 